\title{
Fiesta y ciudad en las noticias sobre la proclamación de Carlos IV *
}

\author{
VICTORIA SOTO CABA
}

Si el género de las "Relaciones" encontró en el período barroco y en la sociedad del Antiguo Régimen su mejor campo de cultivo, a finales del siglo XVIII la multiplicación de aquellos impresos aparece como una de las características más destacadas de tal género literario. Frente a las ediciones de lujo, decisivas pero escasas, que tanto en Madrid, Sevilla o Barcelona sirvieron para plasmar las fiestas de inauguración de los reinados Borbones ${ }^{1}$, en 1789 nos encontramos ante un importantísimo número de Relaciones y Descripciones relativas a la exaltación al trono de Carlos IV. Se trata de un aumento de ejemplares que obliga a reconsiderar las esperanzas puestas en el nuevo monarca por parte de una sociedad que, aún heterodoxa y pluralista en concepciones, había iniciado una andadura programática ilustrada y la reclamaba para el nuevo reinado. Efectivamente, la proclamación de Carlos IV fue uno de los acontecimientos más festejados en la España del siglo XVIII, tanto en ciudades populosas como en las más alejadas villas; pero si el aumento numérico de las Relaciones que lo atestiguan no tiene parangón con las ediciones de reinados anteriores hay que señalar, sin embargo, que lo que se ganó en cantidad se perdió en calidad.

* Parte de este texto se presentó en una comunicación al VII Congreso de Historia del Arte (CEHA), Murcia, octubre de 1988.

Destaquemos La Máscara Real ejecutada por los Colegios y Gremios de la Ciudad de Barcelona para festejar el feliz y deseado arribo de Nuestros Auqustos Soberanos Don Carlos III y Doña Maria Amalia de Sajonia, con el Real Principe e Infantes (Barcelona, 1764), uno de los mejores libros de fiestas del siglo XVIII. 
A excepción de algunos casos, ligados a ciudades de considerable relieve social y económico y entre ellas naturalmente la Corte ${ }^{2}$, la mayoría de las Relaciones de 1789 no son más que folletos anónimos, modestos y breves, de escasas páginas y carentes de estampas, características bien pobres si se tiene en cuenta que fue la Imprenta Real de Madrid la encargada de editar las crónicas de aquel acontecimiento en la mayoría de las ciudades y villas hispanas ${ }^{3}$. De ahí que muchas veces el encabezamiento no sea el de Relación, sino el de "NOTICIA", término que explica mejor la brevedad y la naturaleza concisa de estos textos. Sin embargo, no es tanto la apariencia de tales ediciones el aspecto que más nos preocupa como las concomitancias y las pretensiones narrativas tan patentes en semejante cúmulo de "planfletos", rasgos que ya fueron señalados por el profesor Don Antonio Bonet al avisar que «quien ha leído una Relación puede decir que ha leído todas...", señalando también que precisamente «es en su calidad de serie... donde reside su máximo interés..." ${ }^{4}$.

Por lo general, la fiesta ha sido estudiada en función de su soporte literario, sobre todo cuando éste incluye estampas o proporciona una descripción más o menos completa de los ornatos efímeros. Ésto ha originado que muchos festejos "provincianos" hayan quedado relegados a mera apoyatura erudita o a engrosar simplemente las fichas de una catalogación, al margen de los numerosos artículos que sobre el tema han sido publicados en los últimos años. Pero es, quizá, en esa matización de "provincianismo", intrínseca a los folletos que mencionamos, donde surge un nuevo código para descifrar otros problemas subyacentes en la fiesta del Antiguo Régimen.

Al analizar las Relaciones referentes a Cáceres o La Coruña, Málaga - Murcia, Ibiza o Cuenca, Orihuela o Marbella, Palencia o Soria, por citar tan solo algunos de los ejemplares consultados, se observa de inmediato la homogeneidad de este tipo de crónica, es decir, la narración reiterada de un prototipo de festejo con una serie de ingredientes festivos -o programa de fiestas - que se van repitiendo con variaciones sólo de

2 Además del libro editado en Madrid (Ver Supra, Bonet Corea, A.), es de destacar la Relación sevillana, escrita por Gı, Manuel, Relación de la proclamación del Rey Nuestro Señor Don Carlos IV y fiestas con que la celebró la muy Noble y muy Leal ciudad de Sevilla. Madrid, Imprenta Joaquín Ibarra, 1970.

${ }^{3}$ Las treinta y tres relaciones consultadas salieron de la Imprenta Real de Madrid entre 1789 y 1791, a excepción de la relativa a Ibiza (Barcelona: por Francisco Suriá y Burgada, Impressor Real, Calle de la Paja).

"Bonet Correa, Antonio, "La Fiesta Barroca como práctica del poder", Diwan, núm. 5/6, 1979, págs. 53-85. 
detalle de una villa a otra. No obstante, esta apreciación tan evidente para todos se inserta en un problema más complejo cuando se intuye que la finalidad de la crónica es la de demostrar que se ha cumplido con un precepto real. $Y$, en efecto, ninguna Relación olvida mencionar la Cédula Real que precedía a todo festejo y que exigía la Jura o el acatamiento al nuevo soberano, puesto que, en definitiva, las proclamaciones no eran más que una ceremonia obligada, no publicada en Cortes pero obedecida en calidad de cartas reales ${ }^{5}$.

El acto de la Jura y del levantamiento del Pendón Real constituyen, pues, la trama esencial de la crónica y de la fiesta y, en muchos casos, habría que pensar que gran parte de los ornatos, cabalgatas y regocijos señalados fueron, en más de una ocasión, adiciones del escribano. Es cierto que las proclamaciones de Carlos IV en muchas ciudades revistieron una pompa sin precedentes, reflejo de la prosperidad económica de la España del momento, asi como de los decretos en favor de ciertas clases y del perdón de los atrasos en las contribuciones ${ }^{6}$. Frente a estos casos, la brevedad y las concisas referencias a las "sólidas máquinas" y "ricas construcciones" erigidas en Reinosa, Chinchilla o Guadix permiten la duda, al menos de tales adjetivos. Las frecuentes menciones a la penuria municipal o a las malas cosechas revelan, ya no sólo el esfuerzo corporativo de todos estos actos o festejos, sino también un matiz que difumina posibles espectativas artísticas. Pero, con todo, la "fiesta" existió en una $u$ otra villa, con mayor o menor virtuosismo o esplendor. $Y$ esta certeza, motivada por ese carácter de obligatoriedad que comporta la proclamación real, nos lleva a preguntarnos cual fue el verdadero alcance y el sentido de las numerosísimas fiestas de 1789.

Para empezar habría que comentar el tono laudatorio de estos impresos anónimos amen del marcado carácter político de una proclamación. Al fin y al cabo, ésta no es más que un acto donde los diversos estamentos de la ciudad se reunen "para prestar al soberano el debido vasallaje". Un vasallaje que se acentua en casos concretos, como ha indicado la profesora María Dolores Aguilar en relación con las fiestas de Málaga, cuando precisamente la comisión organizadora, es decir, el Teniente Alférez Mayor, los Regidores y el Sindico Procurador General fue-

"Véase Martinez-Barbeito, Carlos, "Las Reales Proclamaciones en La Coruña durante el siglo XVIII". Revista del instituto JósE CORNIDE de Estudios Coruñeses, Año I, núm. 1. 1965, págs. 11-63.

${ }^{6}$ Así lo explicó también Gomez de ARTECHE, José, El reinado de Carlos iv, Madrid, 1984, Tomo I, págs. 23-24. 
ron nombrados para sus cargos por el nuevo rey y al que debían acatamiento ${ }^{7}$.

Mientras que los ingredientes que conforman la fiesta se presentaron como soluciones optativas, fluctuantes de una villa a otra, bien se trate de ornatos arquitectónicos, cabalgatas, mascaradas, músicas, combates o fuegos artificiales, lo que nunca varió, por el contrario, fueron los pasos reglamentarios de la proclamación en si. Como veremos, estos actos van a dirigir el transcurso de todo el festejo.

El elemento primordial de toda proclamación es la comitiva cuyo trayecto a lo largo de la ciudad no sólo marca las pautas protocolarias del acontencimiento sino que circunscribe el marco lúdico, artístico en esencia, de la fiesta. En las Relaciones, las referencias a este séquito son obligadas. Ninguna crónica olvida mencionar este desfile, como tampoco sus integrantes el "aderezo", la música o la marcialidad que llevaban. Su carácter amplio y heterógeneo es puntualmente señalado en todas las descripciones. Si bien, en algunos casos, el relato diluye las alusiones a los aspectos artísticos del festejo, siempre detalla el número de los participantes, sus cargos, su vestimenta e incluso nombres y apellidos. Se trata de un séquito civil y militar que en muchas Noticias, como las relativas a Belinchón ${ }^{8}$ o Reinosa ${ }^{9}$, por ejemplo, acapara la totalidad del relato. No hay porqué relegar la función de este elemento, ya que, por un lado, será una de las perspectivas más vistosas de la fiesta y, por otra parte, su dinámica a lo largo de la villa o ciudad será esencial como motor de transformación urbana, puesto que su recorrido marcará la denominada "carrera", el núcleo o, mejor dicho, el eje de todo el festejo.

A ello, hay que añadir su papel carismático y regulador de las tensiones sociales. Ante un pueblo que asiste a la festividad y que participa en determinados y controlados "regocijos", la comitiva oficial asume un rol preponderante y bien distinto al de los espectadores. El séquito se convierte en la propia representación, cuya escena no es más que los tapices y las fachadas que adornan la "carrera».

${ }^{7}$ Ver Agular, María Dolores, “Málaga: Imagen de la ciudad en la proclamación de Carlos IV" en las Actas del Congreso El Arte en las Cortes Europeas del siglo XVIII, Madrid, 1989 , págs. 11 y ss. Véase también Escalera Pérez, Reyes: “Fiestas por Carlos III en Granada y Málaga", Boletín de Arte, núm. 10, 1989 págs. 141-156.

${ }^{8}$ Noticia de las fiestas celebradas por la Villa de Belinchón, provincia de Toledo, obispado de Cuenca, en la colocación del retrato del Sr. Rey D. Carlos IV. En las Salas Capitulares de su Ayuntamiento, Madrid, en la Imprenta Real, 1791.

${ }^{9}$ Noticia de las fiestas celebradas por la MIN y L. Villa de Reynosa en la proclamación del Señor Rey Don Carlos IV, Madrid, en la Imprenta Real, 1790. 
La importancia de las comitivas en las funciones festivas ciudadanas no es una novedad en 1789. No hay más que recordar el papel que asumieron las procesiones en las festividades religiosas desde los inicios de la edad moderna. Aunque la modalidad procesional existe ya en la mentalidad medieval, desde el siglo xvı, como ha visto la profesora Palma Martínez-Burgos, la fiesta religiosa "es el orden, claramente jerarquizado, con que desfilan los diversos estamentos, en donde queda recogida la memoria colectiva de la ciudad... ${ }^{10}$. Un papel con peculiaridades propias fue asumido igualmente por los séquitos o cortejos funerales, expresión clara del protocolo cortesano y auténtica simbolización de la imagen de la muerte ${ }^{11}$. Sin duda, el Barroco fue la época del esplendor de las formas procesionales. Ahora bien, a lo largo del siglo XVIII el incremento de los estamentos civiles y militares en las comitivas transforma el antiguo "triunfo" en una marcha de marcado sentido cívico, en donde el simbolismo apoteósico de las antiguas entradas da paso a una cabalgata política. La preponderancia de las clases más fuertes, sobre todo de aquella nobleza que monopolizaba los cargos representativos del gobierno, de entidades municipales juzgados, etc... «sujetos de distinción" como señalan las crónicas, y la presencia abrumadora de la caballería en regimientos, partidas y piquetes desplazan al viejo séquito interestamental. Apenas se menciona el clero en las comitivas de 1789, aunque el patrocinio de la Iglesia siguiera siendo fundamental en los preparativos de la fiesta. Cuatro capellanes en la villa de San Felipe ${ }^{12}$ o una cofradia en Murcia ${ }^{13}$ son las escasas referencias encontradas sobre la integración eclesiástica en las fiestas de proclamación de Carlos IV, frente a un número de más de cien soldados que formaron muchas de las comitivas ciudadanas.

Tan solo los gráficos o croquis pueden darnos una idea de la extensión de esta marcha, a caballo y en columnas de dos, y sobre todo la

${ }^{10}$ Martinez-Buagos, Palma, "Imágenes del Paraiso (Notas a la iconografía de la fiesta religiosa del siglo XVI)", Boletín de Arte, núm. 10, 1989, págs. 59-73. Cfr. además del número dedicado a "Les processions" en La Maison-Dieu, núm. 43, tercer trimestre, 1955.

$"$ Cfr. Soto CABA, Victoria, "Los cortejos en los funerales reales del Barroco: Notas en torno a su origen y configuración", Boletin de Arte, núm. 10, 1989, págs. 121-140.

${ }^{12}$ Noticia circunstanciada de las fiestas de Real Proclamacion del señor Rey Don Carlos IV, executadas por la MI. Ciudad de San Felipe on el Reyno de Valencia. En los dias 28, 29 y 30 de abril de 1789, Madrid, en la Imprenta Real.

${ }_{13}$ Relación sucinta De las Solemnes honras que hizo la ciudad de Murcia á la buena memoria de su difunto Rey el Sr. D Carlos III: de las fiestas con que se proclamó por su Soberano al Sr. Rey D. Carlos IV: y de las demostraciones de sentimiento que manifestó la Real Sociedad económica de amigos del Pais en la muerte de su augusto fundador el dia que cumplia el año de su fallecimiento, Madrid, en la Imprenta Real, 1790. 
incorporación protocolaria de regidores, alguaciles, caballeros, jueces, secretarios, porteros, reyes de armas, maceros, etc... estratégicamente ordenados y resguardados por oficiales y soldados, compañía de Dragones o Granaderos que iniciaban y finalizaban la marcha. Resulta sintomático que casi todas las Noticias detallen pormenorizadamente la ordenación de principio a fin de esta cabalgata civica, aunque tales puntualizaciones tampoco plantean ninguna novedad en 1789 , ya que el género de las Relaciones destacó desde sus orígenes la importancia del protocolo en los ceremoniales.

El orden de la marcha y el de sus participantes es recalcado en las crónicas como punto esencial, permitiendo comprobar que el esquema nunca fue igual. No conocemos si para estos casos existió un patrón como el que en Madrid normalizaba las entradas o salidas de los reyes y su familia, reglas pertenecientes a la etiqueta cortesana ${ }^{14}$ y que fueron mantenidas y seguidas en las comitivas reales con ciertas alteraciones en la práctica a lo largo de los siglos XVII y XVIII. En las ciudades, motivaciones de orden múltiple - sociales, económicas, demográficas - influyeron en la diversidad de estas marchas, sobre todo desde el punto de vista numérico. No obstante, la ordenación mantiene en las villas una graduación simiiar en la que las autoridades decisivas de la proclamación, es decir, alférez mayor y gobernador, corregidor y regidores, eran precedidos por los distintos oficios municipales, maceros y reyes de armas. De ahí, que sea ocioso, intentar proponer un esquema cuando siguiendo unas pautas generales de etiqueta ciudadana, cada lugar optó por una determinada ordenación. Es lógico, pues, que en Murcia, según la Noticia consultada se formará un séquito fúnebre para las exequias de Carlos III con los mismos integrantes de la comitiva de la proclamación de su sucesor, apenas variando el número y lugar.

Si como se ha mencionado anteriormente las Noticias suponen la demostración más patente de que la preceptiva real ha sido cumplida, las referencias al séquito lo testifican aún más, puesto que su misión era la de trasladar el Estandarte o Pendón Real a través de la ciudad para la Jura. Ahora bien, en el caso de muchas crónicas la narración de la comitiva parece ser, más que nada, una compensación ante la pobreza y la escasez de recursos festivos de una determinada villa. En este sen-

${ }^{14}$ El ceremonial de Corte fue fijado por Real Decreto de Felipe IV en 1647. De las numerosas etiquetas manuscritas existe una copia en el Archivo del Palacio Real (Sección Histórica, caja 51) con los planos y plantas de los cortejos para las diversas salidas y entradas de los monarcas. Cir. el estudio de TOVAR MARTin, Virginia en el Catálogo de la Exposición Juan Gómez de Mora, Madrid, Museo Municipal, 1986 
tido, se comprende el afán por resaltar la compostura, la pompa y la vistosidad de la marcha. Así, en Carmona, no se vió nunca tanto «decoro y majestad en el paso", ni tanta "riqueza y hermosura en los jaeces de los caballos", señalando la "uniformidad y decencia de los vestidos de los capitulares" ${ }^{15}$. Será, precisamente, en la vestimenta donde las Noticias hagan más hincapié, detallando alardes textiles en detrimento de otras explicaciones: maceros vestidos "a lo persa", miembros de los juzgados "a lo Romano", y el pleno del Ayuntamiento de negro "con chupas y escarapelas blancas", nos dice el relato de Belinchón. "Uniformes de grana guarnecidos de galón de plata", golillas, togas, damascos y dalmáticas, sombreros, plumas y tocados de seda constituyeron el aderezo de las comitivas y el suficiente alarde para las breves Noticias provinciales. La incorporación de bandas de música, clarines y timbales hizo de esta marcha un buen argumento para dar la suficiente solemnidad al acto de la proclamación.

Desde el punto de vista político la comitiva era imprescindible, pero más decisiva fue su relación con el ámbito urbano. Su trayectoria por calles y plazas marcaba la "carrera", por lo que la elección del recorrido fue un asunto primordial. Será, lógicamente, la zona más noble de la villa, colindante a edificios oficiales, lugares despejados y amplios, encrucijadas, plazas... También bordeará palacios, casas y propiedades de aquella nobleza que participaba en la marcha y cuya economía permitía ornamentar y decorar el trayecto. La relación 0 , más bien, la identificación entre la carrera y una zona urbana determinada resulta de particular interés. En este sentido hay que subrayar el estudio del profesor Carlos Sambricio a propósito de las fiestas celebradas en Madrid durante el reinado de Carlos III, en donde analiza la transformación del espacio urbano madrileño en la segunda mitad de la centuria a través de los itinerarios de los cortejos festivos, comitivas que cambian y evolucionan y que, aunque no varian sustancialmente su itinerario, enfatizan y potencian nuevos tramos urbanos en función de las nuevas construcciones ${ }^{16}$.

No siempre las escasas referencias de las Noticias permiten una respuesta exacta, aunque el caso de Murcia es sintomático de una elección urbana bien específica. La comitiva "se encaminó por las calles regulares desde las Casas Consistoriales a la plaza de Santo Domingo».

${ }^{15}$ Noticia de las fiestas que celebró la muy Noble y muy Leal Ciudad de Carmona en la Augusta Proclamación del Rey Nuestro Señor Don Carlos IV. Madrid, en la Imprenta Real, 1790.

i6 Sambricio, Carlos, "Fiestas en Madrid durante el reinado de Carlos IIl" en el Catálogo de la exposición Carlos III. Alcalde de Madrid, 1788-1988, Madrid, 1988, págs. 549628. 
La alusión a esta regularidad marca ya un trayecto ajeno a ciertos entramados urbanos de la ciudad hispana de la centuria anterior, caracterizada por la irregularidad y la estrechez de las calles. Aunque las proclamaciones de los monarcas del siglo XVII también recorren los puntos neurálgicos de la ciudad, durante el siglo XVIII el recorrido cambia, como el caso de Málaga ${ }^{17}$, o el de Madrid, ciudad en la que, como ha estudiado el profesor Sambricio, «la llegada de Carlos III implica un itinerario que rompe con una ciudad entendida desde la imagen del Madrid de los Austrias y se opta porque el cortejo pase frente a los grandes proyectos arquitectónicos que estaban modificando la imagen de la ciudad...» ${ }^{18}$. En casi todos los casos recogidos el itinerario de la marcha coincide con las zonas donde la elaboración arquitectónica tuvo un mayor despliegue. Así lo indican desde el principio los numerosos bandos municipales proclamados tras la llegada de la carta real: en Belinchón se exigió "esmero en el adorno de las casas y calles donde habia de pasar la cabalgata", petición que, en algunos casos, convierte el trayecto en la única zona festiva $y$, en otros, planta una serie de reformas imprescindibles para el paso del séquito oficial. Fue el caso de la villa de Chinchilla donde "se hizo reparar todo lo necesario y blanquear los edificios" ${ }^{19}$. Más detallada resulta la Noticia de la Proclamación en la villa valenciana de San Felipe, en la que la carrera se presenta "circuyendo la ciudad con más de media legua de extensión" y en la que fue necesaria una serie de reformas. Además de enlucir y pintar gran número de edificios, se eliminaron "los postes y embarazos de las calles y saledizos de algunas casas en la Calle Mayor que la obscurecian", así como "todas las rexas baxas que tantos años... servian de peligroso estorbo". Sin embargo, el derribo de casas "en número de cinco compradas de efectos de Propios dieron un crecido y deseado ensanche". Limpieza y pintura de casas y calles debió ser una medida muy común en los preparativos de la fiesta, pero la última reforma señalada, es decir, la demolición de casas, no parece que fuera seguida por todas las ciudades en 1789. Más bien cabe hablar de una medida poco usual cuya proyección, "dexar la ciudad con un nuevo y agradable aspecto para lo venidero" ${ }^{20}$, nunca interesó a los organizadores y comisarios de los festejos.

17 Aguilar, Maria Dolores, obra citada, pág. 14.

${ }^{18}$ Sambricio, Carlos, obra citada, pág. 557.

${ }_{19}$ Noticias de las Fiestas Celebradas por la MN y ML ciudad de Chinchilla en la proclamación del Señor Rey D. Carlos IV. Madrid, en la Imprenta Real, 1789.

${ }^{20}$ Noticias circunstanciada de las fiestas de la Real Proclamación del Señor rey Don Carlos IV, executadas por la MI Ciudad de San Felipe.... obra citada, s. p. 
Para el caso de Italia, muchos estudios señalan la influencia que la fiesta tiene sobre el entramado urbano ${ }^{21}$, sin embargo y al menos en el caso hispano la fiesta no varió la faz de la ciudad. Tan sólo fue un "afán escénico", una arquitectura de "camuflaje» y una transformación momentánea. Ni siquiera en lo que respecta a la arquitectura efimera puede hablarse de consecuencias directas en la realidad arquitectónica de la ciudad ${ }^{22}$. El carácter tardobarroco en las perpectivas levantadas fue casi una premisa en las fiestas de proclamación de Carlos IV. Columnas salomónicas, literatura emblemática, altares, cornucopias, etc... son los elementos que conformaron los escenarios de Soria ${ }^{23}$, La Coruña ${ }^{24}$ o en la mayoría de las ciudades americanas ${ }^{25}$. Frente al derroche de algunas villas que promovieron construcciones en buena parte del ámbito urbano, en otros casos el ornato se reduce a la instalación de tapices y colgaduras en las fachadas. De siempre se ha cuestionado la credibilidad de los autores a la hora de narrar las magníficas arquitecturas y pasmosas invenciones de la fiesta. El equivoco y la duda se multiplican cuando la crónica ni siquiera especifica "los preciosos adornos" y se contenta con la mención de «no haber ni una casa que dexase de colgarse con telas de seda", como en la Noticia sobre Marbella ${ }^{26}$, comentario que puede calificarse de "coletilla literaria", tan típica en el género de las Relaciones.

${ }^{21}$ Cfr. Allegrı, Luigi, "La città vestita. Macro e microfestività di apparato nella Parma del '700". Storia Urbana. Aivista di studi sulle transformazioni della città e del territorio in étà moderna, Anno X, núm. 34, gennaio-marzo, 1986, págs. 97-123; y Molı FriGol.A, Montserrat: "La ciudad ideal de Carlos de Borbón. Proyectos urbanisticos para las ciudades de Roma y Nápoles en las fiestas de la hacanea (1738-1759)" en las Actas del Congreso Internacional sobre Carlos III y la llustración, Tomo III "Educación y Pensamiento", Madrid, 1989, págs. 305-369.

22 Vease "La última arquitectura efímera del Antiguo Régimen", estudio introductorio del profesor Bonet Correa a la edición facsimil de la Descripción de los Ornatos Públicos de Madrid en la coronación de Carlos IV. Barcelona, Gustavo Gili, 1983.

${ }_{23}$ Noticia de las funciones que se han hecho en la ciudad de Soria, cabeza de provincia y de voto en Cortes, en estos Reynos de Castilla, con motivo de la proclamación del Sr. Rey Don Carlos IV, en los dias 29, 30 y 31 de julio y de 1 de Agosto 1789, Madrid, en la Imprenta Real, 1789.

${ }_{24}$ Noticia de las fiestas que celebró la ciudad de La Coruña en la Augusta Proclama. ción del Sr. D. Carlos IV, Madrid, en la Imprenta Real, 1789.

${ }_{25}$ Como la Noticia de las fiestas celebradas por la MN y ML y Valerosa Ciudad de la Plata, en el Reyno del Perú, en la Proclamación del Serior Rey Don Carlos IV. El dia 26 de septiembre de 1789. Madrid, en la Imprenta Real, 1791; o Noticia de la proclamación del Señor Rey Don Carlos IV y de las fiestas con que la celebró la villa de Moquequa, en el Reyno de Perú, obispado de Arequipa, Madrid, en la Imprenta Real, 1791.

${ }^{26}$ Noticias de las fiestas de Real Proclamación del Señor Rey Don Carlos IV. Executadas por la Ciudad de Marbella en la Costa del Reyno de Granada en los dias 11, 12, 13 y 14 y 15 de Febrero de 1790. 
Dejando al margen los problemas de renovación artística, que la historiografía ha adjudicado a la arquitectura efímera, y la fiabilidad literaria de los folletos editados, hay que volver a insistir en el tema del trayecto y su relación con el entramado urbano para entender la verdadera dimensión de muchos festejos provincianos. Tanto si el curso procesional eligió las calles regulares o bordeó el perimetro de la ciudad, siempre se apropió de los lugares más representativos, de las zonas neurálgicas de la villa y de los edificios oficiales. Incluso si es posible hablar de ciudad ilusoria, no cabe duda de que en muchos ejemplos la ficción sólo se operó en la "carrera". Es el "eje del poder" que atraviesa intencionadamente conventos e iglesias, palacios y mercados, plazas y arrabales. De ahi que sea posible en una determinada ciudad comprobar esa zona representativa, es decir, analizar el lugar por donde a lo largo de festividades pasaron las diversas formas procesionales y su relación con las transformaciones urbanas. La fiesta, la "carrera" y la comitiva son un "diafragma", citando a Maurizio Fagiolo, que proyecta no sólo nuevas formas para la ciudad, sino también nuevos lugares ${ }^{27}$. Problemático y dificil sería intentar identificar la carrera con una exclusiva zona urbana o relacionar la parte más noble de la ciudad -o la más popular- con áquella, puesto que el séquito oficial de la proclamación actuó como motor aglutinante de unos barrios con otros. En este sentido, hay que volver a entender la fiesta como un acto protocolario.

La trayectoria de la comitiva no sólo estaba en función de los lugares más representativos y edificios oficiales, sino que su itinerario debía unir las tres zonas donde se celebraba el acto de la Jura. Se trata casi siempre de plazas o encrucijadas de cierta extensión para poder congregar a un público numeroso, tal y como se indica en Carmona donde la proclamación se ejecutó consecutivamente en la Plaza Mayor, frente a la fachada de los Reales Alcázares y en la Plaza Arrabal. Estos lugares son calificados por las mismas Noticias como "los principales sitios de la carrera».

La mecánica de la proclamación fue muy similar, por no decir casi idéntica, en todas las ciudades y villas. El séquito partia de las Casas Consistoriales al frente de un gobernador o corregidor y un alférez, este último encargado de portar el Pendón Real. Muy próximo a las Casas Consistoriales, por lo general en la Plaza Mayor, se ejecutaba

${ }^{27}$ Cfr. Fagiolo Dell'arco, Maurizio, "Le forme dell'efimero", Storia dell'Arte Italiana, vol. IV, t. II, Torino, 1982. pág. 215. 
la primera proclamación o tremolación del Pendón. Tal fue el caso de Soria, Guadix ${ }^{28}$, Cáceres ${ }^{29} \circ$ Málaga ${ }^{30}$, por citar algunos ejemplos. Finalizada la primera proclama, la comitiva se dirigía al segundo lugar de la jura y, por último, a un tercer enclave, siendo corriente que pasara además por la iglesia catedral para bendecir el estandarte. No obstante, algunas Noticias indican un orden inverso, como en Ibiza que se inició la Jura en la Plaza Real del Castillo, siguió en la Plaza de la Marina y, finalmente, frente a las Casas Consistoriales ${ }^{31}$, o bien señalan una sóla proclamación como la Noticia sobre Murcia, donde la Jura se celebró en la plaza de Santo Domingo.

Las crónicas también comentan pormenores cuando por diversas causas la actuación no pudo celebrarse ante las Casas Consistoriales como en Badajoz, que "por estar inservibles y amenazando ruina" los comisarios decidieron construir "en el campo de San Francisco, una vistosa plaza de madera, que formando un perfecto círculo, con balcones pintados de varios colores, manifestaba en uno de sus frentes la perspectiva de las dichas Casas Consistoriales" ${ }^{32}$.

De la misma manera, las Noticias insisten en resaltar el lucimiento y el decorado que presentaron las fachadas del ayuntamiento. Era algo primordial, aunque fuera en detrimento del resto de los ornatos de la ciudad. En Cáceres se adornó "suntuosamente toda la fachada y balcones con damascos y otras colgaduras"; en Orihuela se incluyeron estatuas $^{33}$; en Cuenca se reconstruyó el interior de las Casas Consistoriales con pinturas al fresco y "adornos de orden compuesto" ${ }^{34}$; en Mar-

${ }^{28}$ Noticia de las fiestas celebradas por la ciudad de Guadix en la proclamación del Sr., Rey D. Carlos IV, Madrid, en la Imprenta Real, 1789.

${ }^{29}$ Noticia de las funciones que ha executado la MN y ML Villa de Cáceres, en la proclamación del Señor Rey Don Carlos IV. El dia 25 de Agosto. Madrid, en la Imprenta Real, 1789

${ }^{30}$ Noticia de las fiestas que la ciudad de Málaga celebró la Augusta Proclamación del Rey N. Sr. D. Carlos Quarto en 16 de mayo de 1789.

${ }^{31}$ Relación de las fiestas que celebró en los dias 25, 26 y 27 de julio de 1789, la ciudad y real Fuerza de Iviza en la Augusta Proclamación del Señor Rey D. Carlos Quarto. Sale a la luz por disposición del muy llustre Ayuntamiento. Con licencia. Con licencia. Barcelona: Por Francisco Suriá y Burgada, Impresor Real, calle de la Paja.

${ }^{32}$ Noticia de las fiestas celebradas por la MN y ML Ciudad de Badajoz en la proclamación del Señor Rey Don Carlos IV, Madrid, en la Imprenia Real, 1789.

${ }^{33}$ Noticia de las fiestas celebradas en la ciudad de Orihuela con motivo de la proclamación del Sr. Rey D. Carlos IV, en los dias 1. 2. 3. y 4. de septiembre de 1789. Madrid, en la Imprenta Real, 1790.

${ }^{34}$ Noticia de las funciones executadas en la MN y ML Ciudad de Cuenca, con motivo de la proclamación del Sr. D. Carlos IV. Madrid, en la Imprenta Real, en el dia 23 de mayo de 1790. 
bella una "hermosa perspectiva" a base de doseles, pabellones, espejos, arañas y cornucopias; en Reinosa se elevó un arco triunfal y en San Roque se formó «un pórtico de cinco arcos con Pilastras y cornisas toscanas, de las que se elevaban quatro columnas dóricas" ${ }^{35}$. Todo este despliegue no tuvo otro fin que el de servir de escenografía a uno de los elementos esenciales de la proclamación: los retratos reales de Carlos IV y María Luisa que presiden todo el acto y que reciben vítores y aclamaciones. Retratos de muy dudosa calidad y de un carácter popular que, como ha estudiado Emilia Montaner, "adquieren su verdadera razón de ser cuando se contemplan en el contexto del desarrollo de la fiesta". Para esta autora, esta clase de retratos de los soberanos «pierden su función meramente representativa en favor de una pluralidad de significados que pueden resumirse en una ideología general de exaltación del poder", añadiendo que cobran un valor de evocación de la realidad y llegan a sustituir a la presencia física del propio monarca ${ }^{36}$. Esta presidencia simbólica y personalización de la imagen del soberano no sólo estará en la fachada del ayuntamiento, sino que salpica el recorrido y los principales sitios de la carrera, introduciéndose también en los carros de la cabalgata organizada por los gremios, festejo que ponía punto y final al programa de la mayoría de las fiestas de 1789 .

Volviendo a los enclaves donde se celebraba la ceremonia hay que señalar varios aspectos. En primer lugar, fueron barrios apartados entre si y representativos, posiblemente, de una determinada clase ciudadana. Por un dia, la disparidad de las diversas zonas urbanas quedó unificada por el curso procesional incluso presentaron cierta uniformidad por la decoración y el ropaje de la carrera. Los enclaves, lo suficientemente espaciosos como para convocar a toda la población, fueron los puntos de unión de un trayecto que atravesó la ciudad, desde el centro urbano hasta el arrabal, la playa, el camino o la puerta más alejada.

En segundo lugar, hay que tener en cuenta el montaje efímero tan especial que requerian aquellos enclaves. Podría hablarse de un escenario protocolario, debido a las similitudes que presentaban en todas las ciudades. El montaje no era más que un tablado de maderas que servía de apoyo a las formalidades de la Jura. Alli subían el gobernador y el

${ }^{35}$ Noticia de las funciones que ha celebrado la MN y ML. Ciudad de Gibraltar residente en su campo de San Roque, en la proclamación del Señor Rey Don Carlos IV, en Madrid, en la Imprenta Real, 1789.

${ }^{36}$ Montaner, Emilia, “El retrato cortesano en Salamanca y su significado en la fiesta barroca" en las Actas del Congreso El Arte en las Cortes Europeas del siglo XVIII, obra citada, págs. 513-520. 
alférez, se leían las palabras de estilo, se tremolaba el Pendón y se gritaban los Vivas. El tablado, normalmente de planta cuadrada, podía estar "adornado de pasamanos, pilastras, estatuas y balaustradas", como en Málaga, ser "de dos cuerpos» como en Murcia o estar cubierto de alfombras y tapices de terciopelo como en Reinosa o Chinchilla. También podía incluir "una estatua equestre de magnitud extraordinaria", pues asi lo indica la Noticia de Orihuela o adquirir la apariencia de un templo con columnas o de un arco de triunfo, según la Relación ibicenca. $^{37}$

El boato o el desarrollo arquitectónico de tal montaje no fue obstáculo nunca para la función protocolaria; al contrario, estuvo en consonancia con la importancia de la ceremonia. Al fin y al cabo, la Jura al soberano era el acto esencial de la proclamación, la meta de la comitiva $y$ el origen de las fiestas. En el fondo, esto es lo que consta en las breves crónicas de las Noticias. En la mayoría, el relato no hace más que dar las pautas primordiales de la función. La narración de los ornatos no aparecen como un objetivo prioritario, a pesar de que las reminiscencias barrocas se revistieron con esperanzas de progreso y cláusulas ilustradas, reflejo del "celo" de los comitentes y de la buena acogida al nuevo rey. Frente a las esperanzas por continuar un período reformista con Carlos IV, surge la pregunta de si el escenario de las fiestas de 1789 prolongó realmente el marco festivo del barroco, si fue en efecto el último capítulo de la larga tradición festiva del Antiguo Régimen. Ante una fecha tan «revolucionaria» sería muy significativo reconsiderar los nuevos matices que adquiere el acto, tema que mereceria un análisis más detallado. Ciertamente y como señala el profesor Sambricio «la fiesta es la consagración de un rígido protocolo" que evita rupturas y cambios. Sin embargo, en muchas de las crónicas de 1789 se observa ya que el acontecimiento fue, ante todo, una "afirmación política".

${ }^{37}$ Cfr. Pilar Pedraza que, a propósito de las entradas ieales, escribe que: «El esquema no varia, y los entresijos organizativos, apenas: lo que cambia, y muy lentamente, es el ideario que preside el conjunto..." pasando "de la retórica persuasiva y sin aparente fisma del barroco, al didactismo paternalista ilustrado" en "Arte efimero y espectáculo en la corte española durante el siglo XVili, en el Catálogo de la Exposición El Real Sitio de Aranjuez y el Arte Cortesano del siglo xvII, Madrid, 1987, págs. 203-219. 
